\title{
Bacteriophage Morphotypes Isolated from a Unique Coastal Mining Site
}

\author{
K. D. Moulton*, J. L. Jamison*, T. L. Baumgarten*, A. Speth*, L. J. Rothschild**, and S. M. \\ Duboise* \\ * Department of Applied Medical Sciences, University of Southern Maine, 96 Falmouth Street, 178 \\ Science Bldg., Portland, ME 04103 \\ ** NASA Ames Research Center, Mail Stop 239-20, Moffett Field, CA 94035
}

Seasonal studies of microbial and viral biodiversity are ongoing at a former copper and zinc mining site, the Callahan Mine, on Cape Rosier, Maine. When mining operations ceased in 1972, an inlet to the site was opened to allow flooding of the 100 meter deep mine pit by tidal waters from Penobscot Bay which connects into the Gulf of Maine. Adjacent to the flooded areas of the mining site are piles of mine tailings and waste rock from which drainage occurs with elevated levels of heavy metals including cadmium, copper, lead, and zinc. Concerns about metal leaching are high and have contributed to the site being designated a priority site by the United States Environmental Protection Agency [1]. To our knowledge this is the only coastal copper mining site in the world where there is flooding daily by tidal waters. Thus this estuarine site may have unique metal rich habitats such as the stratified depths of the submerged mine pit with distinct microbial and viral biodiversity.

In recent years it has become clear that viruses are the most abundant biological entities on Earth and that bacteriophages are critically important in microbial ecology and genetics $[2,3,4]$. In the studies reported here, bacteria isolated from this coastal mining site have served as potential hosts to be used in enrichment and isolation of bacteriophages from this metal rich site. Bacterial isolates were classified by PCR amplification and sequencing of 16S rRNA genes followed by genetic database comparisons. To enrich for bacteriophages present, estuarine water samples were added to mid-log phase cultures of individual bacterial isolates. Enriched samples were centrifuged to remove bacteria and cell debris, diluted serially, plated on lawns of each specific host bacterium, and repeatedly plaque purified. Isolated phages were negatively stained for transmission electron microscopy (TEM). Selectively, bacteriophage genomic studies are proceeding through nucleic acid purification, genomic library construction, and DNA sequencing. TEM images of bacteriophages isolated from the former mine site are shown in Figure 1 and reveal diverse viral morphotypes including some that are characteristic of tailed phages of the order Caudovirales (Figure 1A, 1B, 1C, 1D, and 1E) but also including some unusual tail-less morphotypes (Figure 1F, 1G, and 1H). Genomic sequence data has shown that the bacteriophage shown in Figure $1 \mathrm{~F}$ which infects a host bacterium most closely related by $16 \mathrm{~S}$ rRNA sequences to Pseudoalteromonas arctica A-37-1-2 is a novel member of the family Corticoviridae, for which only one prototypic virus designated PM2 has been previously characterized [5]. Isolation of several distinct non-tailed phages at the mine site (Figures 1F, 1G, and 1H) suggests that these unusual viruses may be important in the microbial ecology of this metal rich environment.

\section{References}

[1]http://yosemite.epa.gov/r1/npl_pad.nsf/701b6886f189ceae85256bd20014e93d/1cdd147450089bb 585256aca005551e9! OpenDocument 
[2] K. E. Wommack, and R. R. Colwell, Microbiol. Mol. Biol.Rev. 64 (2000) 69.

[3] C. A. Suttle, Nature 437 (2005) 356.

[4] E. Kutter and A. Sulakvelidze, Bacteriophages: Biology and Applications, CRC Press, Boca Raton, 2005.

[5] Index of Viruses - Corticoviridae, In: ICTVdB - The Universal Virus Database, version 4. Büchen-Osmond, C (Ed), Columbia University, New York, USA, 2006. http://www.ncbi.nlm.nih.gov/ICTVdb/Ictv/fs_index.htm

[6] This work was supported by NASA EPSCoR grants EP-07-03 and EP-08-02 and NSF grant CNS-0521262. A. Speth and T. Baumgarten received graduate fellowship support from NSF grant DGE-0440560. The assistance of Naji Akladiss, Maine Department of Environmental Protection, is gratefully acknowledged.

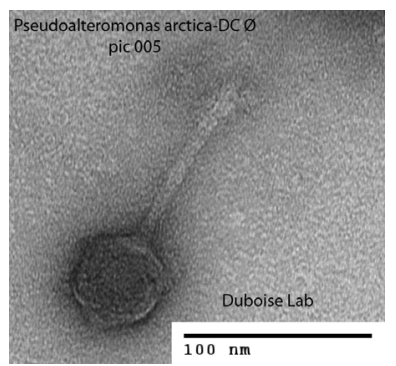

A.

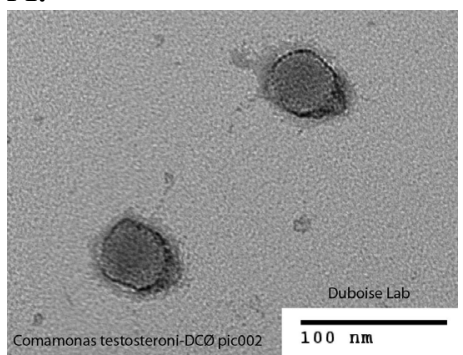

D.

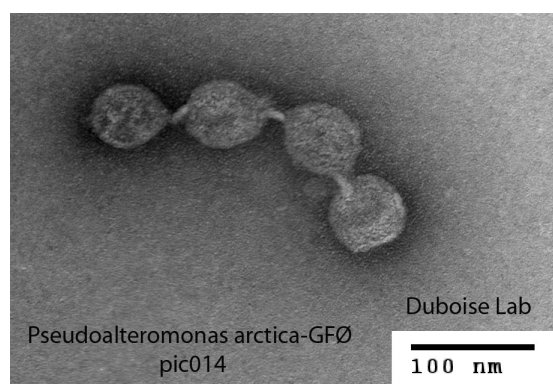

F.

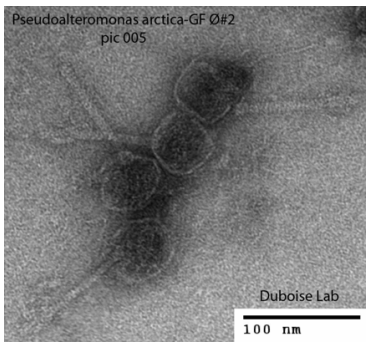

B.

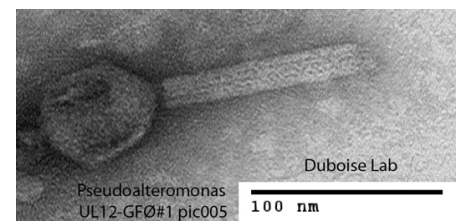

E.

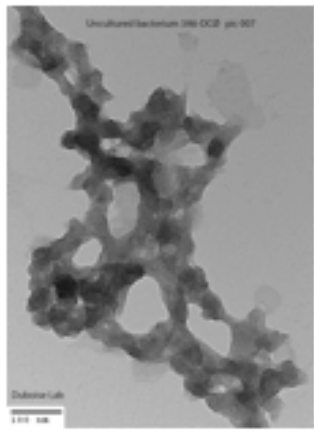

G.

C.
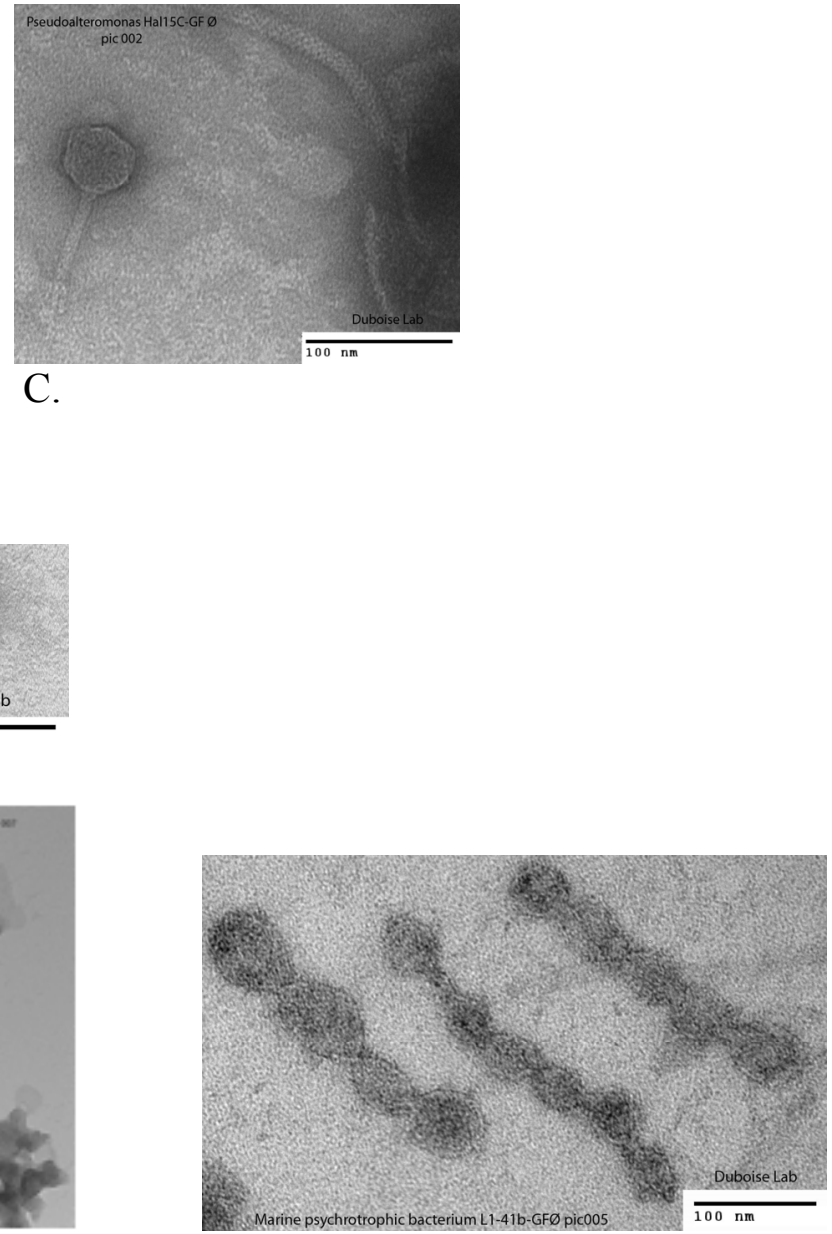

H.

Figure 1: TEM images of negatively stained preparations of bacteriophages isolated from the former Callahan Mine site. Panels A-E show morphotypes consistent with the order Caudovirales, the tailed phages. The major families Siphoviridae (panels A, B, and C), Podoviridae (panel D), and Myoviridae (panel E) all appear to be represented. Panels F, G, and H show three distinct phages with a novel chain-like morphotype. The phage in panel $\mathrm{F}$ has been identified as a new member of the lipid-containing bacteriophage family Corticoviridae. Bacteriophage designations on the micrographs indicate the 16S rRNA based identification of their respective bacterial hosts. 